\title{
Dynamic Characteristics Analysis of a Hydraulic Propeller Controlled by a Servo Valve for Work Class ROV
}

\author{
Fu-xiang Huang1, Xiang Li², Xin-fei Li²* and Yan Guo ${ }^{2}$ \\ ${ }^{1}$ Offshore Oil Engineering Co, Ltd, Tianjin, 300451, China \\ ${ }^{2}$ Harbin Engineering University, Nantong Street No.145, Harbin 150001, China \\ *Corresponding author: Xin-fei Li, Harbin Engineering University, Nantong Street
}

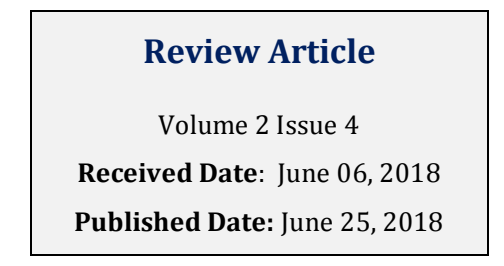

No.145, Harbin 150001, China, Tel: 139-4601-2577; Email: lixinfei@hrbeu.edu.cn

\begin{abstract}
In order to study the dynamic response characteristic of hydraulic propeller control system for a work-class ROV (Remote Operated Vehicle), a dynamic system model for hydraulic propeller controlled by a servo valve is constructed with respect to propeller dynamic load characteristics. A solution method for motor flow, motor pressure, motor speed, propeller torque and thrust is presented. The dynamic response characteristics of hydraulic propeller control system with different control voltages are analyzed by numerical simulation. The thrust constraint model in thrust allocation is constructed, and the nonlinear function relationship between the control voltage and the expected thrust is obtained. Compared with tank test results of hydraulic propeller, the simulation results are accurate and reliable. It is good for motion control, thrust allocation and hydraulic propeller control of underwater vehicles and dynamic positioning ships.
\end{abstract}

Keyword: Work-Class ROV; Thrust Allocation; Hydraulic Propeller; Servo Valve; Dynamic characteristics

\section{Introduction}

The biggest characteristic of a work-class ROV is able to complete high-intensity, high load and high-precision work in the dangerous complex deep-sea environment. The work-class ROV is one of the essential technical equipment to implement the development strategy of deep-sea resources. In order to ensure the ability to work underwater, the work-class ROV needs to achieve the motion control for 4-6 degrees of freedom. The number of propellers in a work-class ROV is generally greater than the number of free degrees you want to control [1]. The work-class ROV needs to control 6-8 hydraulic propellers simultaneously, which has a typical system of over-driven kinetic control. The hydraulic propeller is a typical inertial link which exists hysteresis in the response of controls. If not properly controlled, it's easily cause a phase difference of multiple propeller response so that cause the deterioration of control performances for the ROV and even the failure of underwater tasks; At the same time there are limits of the maximum thrust threshold of hydraulic propellers, the response rate and the response time. This problem [2] must be considered when studying the thrust allocation strategy of the over-driven control system. Therefore, the analysis of dynamic response system of hydraulic propellers controlled by servo valves 


\section{International Journal of Oceanography \& Aquaculture}

has a great significance for kinetic control and thrust allocation strategy of the work-class ROV [3].

Tor A. Johansen [2] gave a particular analysis and comparison for the thrust allocation of over-driven control system, and pointed out that it is necessary to consider the saturated constraint characteristics of the propeller output and the speed limits of increased thrust when the thrust allocation of the over-driven control system is studied. Fossen Thor I [3] gave a more profound comparative analysis for the thrust allocation strategy of the over-driven sea-aircraft and simplified the propeller model as a proportional link with consideration of saturated constraint characteristics. Yang Shi-zhi [4] established a marine propulsive system for dynamic positioning system and a simplified propeller model, carried a study on the method of thrust allocation to minimize the energy consumption. For the breakdown of partial propellers, Serdar Soylu studied an optimal thrust allocation with respect to the saturated constraint characteristics [5]. It can be seen: When the domestic and foreign scholars studied the thrust allocation of the overdriven system, they often assumed that the mathematical model of propeller is a simple proportional link, or considered about the rising rate restrictions of thrusts, but ignored characteristics of the dynamic response system. Liu Xi-jia [6] modeled and simulated the hydraulic propulsive system of the work-class ROV. Wei Yan-hui [7] proposed a design for the propulsive system of the deepsea work-class ROV. Ji Yu-long [8], Ma Lai-hao [9] and Peng Wei established a mathematical model for the marine propeller according to its load characteristics, and gave a numerical simulation of its load characteristics [10]. It can be seen: although some domestic and foreign scholars modeled and simulated the control problems of the hydraulic propulsive system, they did not analyze the dynamic response characteristics of the propulsive control system with consideration of the dynamic load characteristics.

In this paper, according to the deep-sea work-class ROV whose hydraulic propeller is controlled by an electro-hydraulic servo valve, the writer established a mathematical model of the hydraulic propulsive dynamic system controlled by a servo valve with a consideration of dynamic load characteristics. A solution method for motor flow, motor pressure, motor torque, motor speed, propeller torque and thrust is presented. The writer analyzed the dynamic response characteristics for the servo valve, hydraulic motors and propeller with different control voltages when the propeller speed is zero, and then compared the simulation result with the cistern-test results given by the company SMD. A simplified constraint model of thrust was constructed and a mathematical model reflected the relationship between the expected thrust and the control voltage of propeller was established.

\section{The Hydraulic Propulsive System Composition and Main Technical Parameters of Work-Class ROV}

In this paper, taking the Quantum remote-control ROV of British company SMD as the research object analyzes the composition and dynamic response characteristics of the hydraulic propeller controlled by a servo valve. The hydraulic propulsive control system is an important part of the work-class ROV hydraulic systems that ensuring the ROV to achieve the six degrees of freedom motive control which is required by a variety of underwater tasks. The control system of hydraulic propellers comprising: the constant pressure pump, the control unit, the servo valve, the reversing valve, the safety valve, the relief valve, the pressure compensatory unit, the hydraulic motor, the propeller and other components.

Components of the control system for a work-class ROV are shown in Figure 2, the constant voltage source of oil works at a constant pressure ${ }^{p_{\mathrm{r}}}$. The underwater movement of ROV is completed by the instructions of motion control, and then a control amount $\tau$ issued by the appropriate "control method" module is outputted.

Outputting the desired thrust $T e_{i}$ by the " thrust allocation strategy" module, the desired thrust is converted into a control voltage $u_{\mathrm{v}}$ by the "control function of propeller" module, ${ }^{u_{\mathrm{v}}}$ is transformed into the control current ${ }^{i_{\mathrm{v}}}$ of a servo valve by the "pre-amplifier" module, ${ }^{i}$ transforms into the opening displacement of a servo valve through the "proportional amplifier" module. Through adjusting the pressure and flow of servo valve to control the speed and output torque of the hydraulic motor, and then the output of desired thrust is achieved by the rotate of propeller. Finally, the thrust applying to the ROV which makes the ROV moving as desired control commands.

There has 8 hydraulic pipe propellers arranged symmetrically at vector in the Quantum work-class ROV of company SMD. There has 4 vertically and 4 in horizontal direction. The working principle of Work-Class ROV is shown in Figure 1, Quantum series ROV is equipped with 8 hydraulic ducted thrusters, of which 4 are installed in the vertical direction and 4 in the 


\section{International Journal of Oceanography \& Aquaculture}

horizontal direction. The $o_{b}-x_{b} y_{b} z_{b}$ body coordinate system of underwater vehicle [3] is established. The origin ${ }^{o_{b}}$ of the coordinate is taken from the center of gravity of ROV and the coordinate axis $o_{b} x_{b}, o_{b} y_{b} 、 o_{b} y_{b}$ which is respectively consistent with the inertial spindle of ROV. The rated working pressure of the hydraulic system for ROV is 320Bar, maximum working pressure is 350Bar; the theoretical maximum flow of the hydraulic system is about $250 \mathrm{~L} / \mathrm{min}$. Taking into account the impact of the pump efficiency, the actual maximum flow rate of it is $210 \mathrm{~L} / \mathrm{min}$. The theoretical maximum flow for a single set of propeller is $57 \mathrm{~L} / \mathrm{min}$. The model of the horizontal propeller [11] is HTE380BA-32; the model of vertical propeller is HTE300BA-23. The hydraulic motor is an inclined shaft quantitative motor with axial plunger of Rexroth Germany's A2FM series [12]. In this paper, the writer takes the horizontal propeller as an example establishes a mathematical model of the hydraulic propulsive dynamical system $[13,14]$.

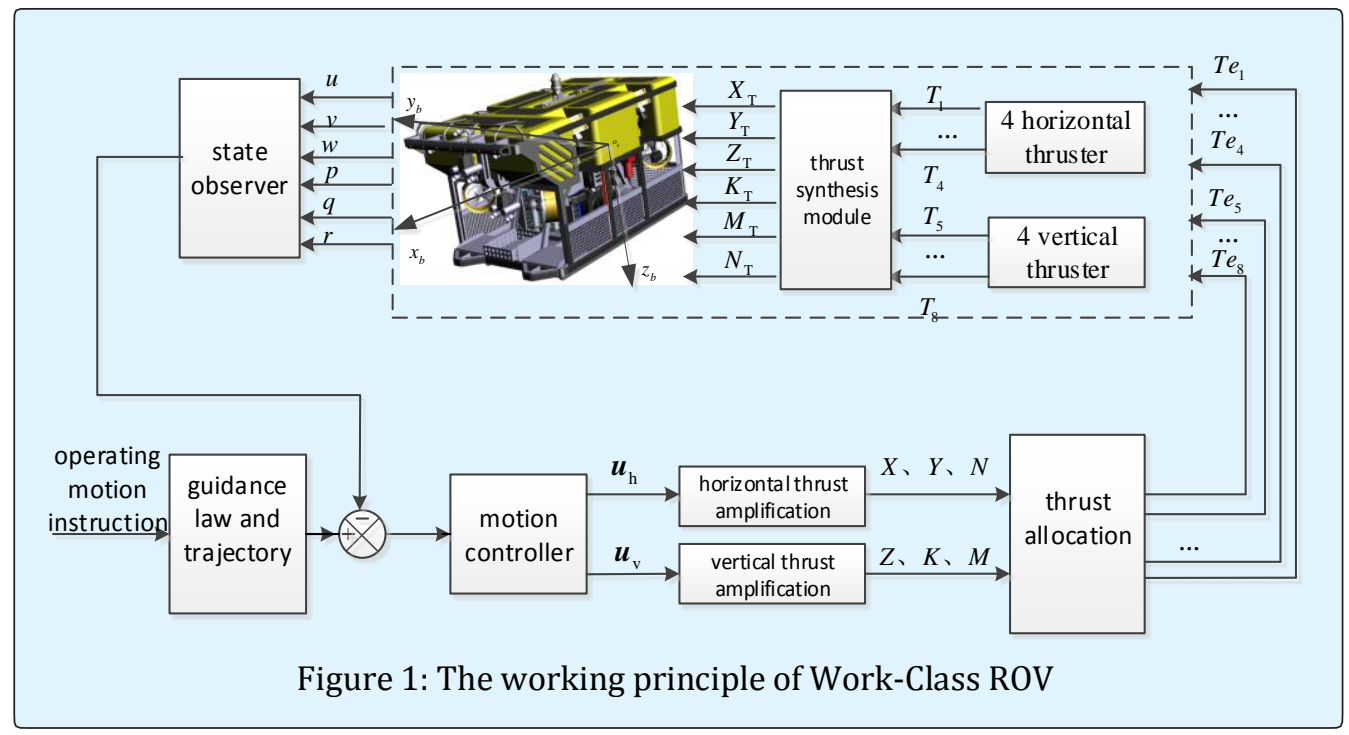

\section{Mathematical Modeling of Hydraulic Propeller Controlled By a Servo Valve}

In order to model the dynamical system of the hydraulic propeller controlled by a servo valve, the writer makes some assumptions as follows:

Simplifying the hydraulic propeller reasonably, ignoring the safety valve, the relief valve and the pressure compensation unit as shown in figure 2;

Ignoring all the short and thick connected pipes, the friction losses in the pipeline, and the impact of fluid mass and the dynamic of pipes;

The fluid temperature and elasticity modulus of bulk are considered constants;

The internal and external bleed of the hydraulic motor are laminar flow.

\section{Mathematical Model of Servo Valve}

The propeller of the remote control ROV studied in this paper is controlled by a electro-hydraulic servo called Model456 which comes from an British company "Star". It can be seen that, when the flow is $60 \mathrm{~L} / \mathrm{min}$, the time constant is $0.012 \mathrm{~s}$; When the flow is $4 \mathrm{~L} / \mathrm{min}$, the time constant of the servo valve is $0.006 \mathrm{~s}$. In order to simplify the model of the servo valve, the time constant is settled to $0.02 \mathrm{~s}$. The input current range of the electro-hydraulic servo valve is $-40 \mathrm{~mA}-40 \mathrm{~mA}$. The displacement range of the plug and seat is $-5 \mathrm{~mm}-5 \mathrm{~mm}$.

So the transfer function of a servo valve for horizontal propeller can be simplified as a first-order inertia link:

$$
G(s)=\frac{0.125}{0.02 s+1}(1)
$$

\section{Mathematical Model of the Hydraulic Motor Controlled by a Servo Valve}

Linearized flow equation of the servo valve: The linearized flow equation of a servo valve worked in the work-class ROV hydraulic propulsive system is: 


\section{International Journal of Oceanography \& Aquaculture}

$$
Q_{\mathrm{L}}=K_{\mathrm{q}} x_{\mathrm{v}}-K_{\mathrm{c}} p_{\mathrm{L}}
$$

Where: $Q_{\mathrm{L}}$-the flow of load oil-fluid, $m^{3} ; P_{L}$-the difference of pressure between the high pressure oil-way and the low pressure oil-way of the hydraulic motor, $P a$; $x_{\mathrm{v}}$-the opening displacement of an electro-hydraulic servo valve core, $m ; K_{\mathrm{q}}$-the flow gain; $K_{\mathrm{c}}$-the flow/pressure coefficients, $\left(\mathrm{m}^{3} / \mathrm{s}\right) / \mathrm{Pa}$.

Because the work-class ROV needs to take complex operations underwater for a long time, so it's workingspeed range is wide. The valve coefficient in formula (2) is not a constant, but fluctuates according to the workingpoint of hydraulic system. But in order to facilitate the analysis, adopting the linearization and regarding that $K_{\mathrm{q}}$, $K_{\mathrm{c}}$ are constants.

Continuity equation of flow for the hydraulic motor: The continuity equation of flow for the hydraulic motor can be written as the following formula [13]:

$$
Q_{\mathrm{L}}=D_{\mathrm{M}} \dot{\theta}+C_{\mathrm{tc}} p_{\mathrm{L}}+\frac{V_{t}}{4 \beta_{\mathrm{e}}} \cdot \frac{d p_{\mathrm{L}}}{d t}
$$

Where: -the theoretical displacement of the hydraulic motor, $\mathrm{m} 3 / \mathrm{rad}$; -the total volume of the cage, the motor chamber and the connecting pipeline, $\mathrm{m} 3$; - the elasticity modulus of equivalent volume, N/m2 (Pa);-the total leakage coefficient of the hydraulic motor, $(\mathrm{m} 3 / \mathrm{s}) / \mathrm{Pa}$; -the angular displacement of the hydraulic motor, rad; -the angular speed of the hydraulic motor, rad/s.

Equilibrium equation of the hydraulic motor and the load torque: According to the modeling assumption, the Coulomb friction coefficient and other torques of nonlinear load are ignored. Due to the external load of the hydraulic motor is not spring-load, and there just has a propeller torque load, so the hydraulic motor only has inertia loads, sticky load and external load torque. According to the Newton's second law, the equilibrium equation of the hydraulic motor and load torque is:

$$
M_{\mathrm{g}}=J_{\mathrm{P}} \frac{d^{2} \theta}{d t^{2}}+B_{\mathrm{M}} \frac{d \theta}{d t}+M(4)
$$

Where: $M_{\mathrm{g}}$ - the output torque of the hydraulic motor, $N \cdot m ; B_{\mathrm{M}}$-the viscous damping coefficient of the spindle for the hydraulic motor, $N \cdot \mathrm{m} /(\mathrm{rad} / \mathrm{s})$; $J_{\mathrm{P}}$-the sum of equivalent inertial moment for the hydraulic motor and propeller, $\mathrm{kg} / \mathrm{m}^{3} ; M$-the load torque acted on the hydraulic motor of the propeller, $N \cdot m$.

The output torque of the hydraulic motor can be calculated as follows:

$$
M_{g}=D_{\mathrm{M}} p_{\mathrm{L}}
$$

Where: $D_{\mathrm{M}}$-the displacement of the hydraulic motor, $\mathrm{m}^{3} / \mathrm{rad}$;

\section{Mathematical Model of Propeller Load}

The work-class ROV usually uses the hydraulic propeller, the load torque of propeller can be calculated as [14]:

$$
M=K_{\mathrm{Q}} \rho n^{2} D^{5}
$$

Where: $M$-the torque of load, $N \cdot m ; K_{\mathrm{Q}}$-the torque coefficient of propeller; $\rho$-the density of seawater, $\mathrm{kg} / \mathrm{m}^{3} ; n$-the speed of propeller, rps; $D$-the diameter of propeller, $m$.

The output thrust of propeller:

$$
T=K_{\mathrm{T}} \rho n^{2} D^{4}(7)
$$

Where: $K_{\mathrm{T}}$-the thrust coefficient of propeller.

The speed coefficient of propeller can be calculated as:

$$
J=\frac{V_{\mathrm{A}}}{n D}(8)
$$

Where: $n$-the speed of propeller, $r p s ; V_{\mathrm{A}}$-the inlet speed of propeller, $\mathrm{m} / \mathrm{s}$.

The thrust coefficient $K_{\mathrm{T}}$, the torque coefficient $K_{\mathrm{Q}}$ and the efficiency $\eta_{0}$ of some propellers which have constant geometrical shape are only related to the intake coefficient $J$. The writer assumes that the velocity of inlet water is zero, the $K_{\mathrm{T}}$ and $K_{\mathrm{Q}}$ are constants.

Basing on the main technical parameters of the horizontal propeller and the hydraulic motor, the main technical parameters of dynamical systems for the horizontal hydraulic propeller controlled by a servo valve can be calculated. The outcomes are shown in Table $[11,12]$. 


\section{International Journal of Oceanography \& Aquaculture}

\begin{tabular}{|c|c|c|}
\hline Symbol & Parameter Name & Value \\
\hline $\mathrm{DM}$ & Displacement of hydraulic motor & $5 \times 10-6$ \\
\hline $\mathrm{J}$ & Moment of inertia of motor shaft and propeller & $10 \times 10-2$ \\
\hline $\mathrm{Kc}$ & flow/pressure coefficient & $13 \times 10-12$ \\
\hline $\mathrm{Ctc}$ & Leakage of the hydraulic system & ------- \\
\hline $\mathrm{Vt}$ & the total volume of the cage, the motor chamber and the connecting pipeline & $0.6 \times 10-3$ \\
\hline $\mathrm{Be}$ & Elasticity modulus of equivalent volume & $7 \times 108$ \\
\hline $\mathrm{Kq}$ & Gain of flow & 0.2 \\
\hline $\mathrm{BM}$ & Moment coefficient of viscous damping & 0.02 \\
\hline $\mathrm{KT}$ & Thrust coefficient of propeller(when the velocity of inlet is zero) & 0.355 \\
\hline $\mathrm{KM}$ & Torque coefficient of propeller(when the velocity of inlet is zero) & 0.0232 \\
\hline
\end{tabular}

Table 1: The main technical parameters of hydraulic propulsive dynamical system controlled by a servo valve. Note: The unit of parameters in (Table 1) accords to the symbol units in this article.

\section{Mathematical Model of the Zoom Link}

In figure 2, "the control function of propeller" module converts the desired thrust signal $T a_{i}$ which outputted from the allocation unit into a control voltage signal $u_{\mathrm{v}}$. The relationship between them is a nonlinear function and can be expressed as shown:

$$
u_{\mathrm{v}}=f\left(T a_{i}\right)(9)
$$

Where: $u_{\mathrm{v}}$-the control voltage.

In figure 2, the circuit of proportional amplifier is driven by the servo valve, it is a voltage - current converter with high impedance output whose band is much higher than the inherent frequency of the hydraulic system. The proportional amplifier can be simplified to a proportional link. Through it out putting a current signal within $-40 \mathrm{~mA}-40 \mathrm{mAto}$ control the displacement of the electro-hydraulic servo valve core. The transfer function of the proportional amplifier can be expressed as:

$$
K_{\mathrm{I}}=\frac{i_{\mathrm{v}}}{u_{\mathrm{v}}}(10)
$$

Where: $i_{\mathrm{v}}$-the control current of a servo-valve.

\section{Simulation of the Dynamical System for the Hydraulic Propeller Controlled By a Servo Valve}

Because there has a complex nonlinear relationship between the thrust of propeller and the inlet speed coefficient, the rotational speed of hydraulic motor, the torque, the oil pressure, there also has a complex nonlinear relationship between the torque of propeller and the inlet speed coefficient, the rotational speed of hydraulic motor, the torque, and the flow. So according to the traditional method of transfer functions, the linearized model between the expected thrust and the actual thrust of propeller can't be established. Therefore, proposing a method to simulate the dynamical system of hydraulic propeller controlled by a servo valve. The method introduces the torque of propeller load into the moment balanced equation of hydraulic motor, solves the flow, the pressure, the torque and the state of rotational speed for the hydraulic motor in real-time; then puts the rotational speed of motor and the inlet speed coefficient into the torque and thrust equation of the propeller, thereby solves the torque and thrust in real-time. As shown in (Figure 2) is a solving method process of the motor flow, the pressure, the torque, the speed, the turning moment and the thrust of hydraulic propeller controlled by a servo valve.

The solving steps for the flow of the hydraulic motor, the pressure, the speed, the torque and the thrust of propeller are given below:

- Firstly, initializing the dynamical simulated system of hydraulic propeller controlled by a servo.

- Secondly, inputting the control voltage $u_{\mathrm{v}}$ to the "proportional amplifier" module, we can calculate the control current $i_{\mathrm{v}}$ of servo valve.

- Thirdly, in putting the control current $i_{\mathrm{v}}$ of servo valve to the" transfer function of servo valve " module ,the opening displacement $x_{v}$ of servo valve can be calculated .

- Fourthly, in putting $x_{\mathrm{v}}$ to the "flow calculation of servo valve" module, the flow $Q_{\mathrm{v}}$ of servo valve at time $t$ can be calculated .

- Fifthly, inputting $Q_{v}$ to the "loaded flow of motor" calculative module, and according to the oil pressure $p_{t-1}$ of the hydraulic motor at time $t-1$, the load flow $Q_{t}$ 


\section{International Journal of Oceanography \& Aquaculture}

of motor at time $t$ can be calculated.

- Sixth, whether the current loaded flow of motor $Q_{t}$ reached the maximum $Q_{\max }$ or not. If reached, the current flow of motor is $Q_{\max }$; if not reach, the current flow of motor is $Q_{t}$.

- Seventh, inputting $Q_{t}$ to the "increasing speed of motor's oil pressure" calculated module, and according to the oil pressure of the hydraulic motor $p_{t-1}$, the angular velocity of motor $\omega_{t-1}$ at time $t$-1, to calculate the current increasing speed of motor's loaded pressure $\dot{p}$ at time t.

- Eighth, inputting $\dot{p}$ to the "motor's oil pressure" calculated module. According to the oil pressure of the hydraulic motor at time $t$ - 1 , the current oil pressure $p_{t}$ can be calculated at time $t$.

- Ninth, inputting $p_{t}$ to the" whether reach the pressure of pump with constant pressure" module. If reached, the current oil pressure of hydraulic motor is the working pressure of hydraulic pump $p_{r}$; if not reach, the current oil pressure of motor is $p_{t}$.

- Tenth, inputting the output torque of motor $M_{g}$ at time $t$ and the loaded torque of propeller $M_{t-1}$, the rotational speed of propeller at time $t-1$ into the "rotational speed of motor " calculated module to calculate the accelerated speed of hydraulic motor $\dot{\omega}$ at time $t$.

- Eleventh, inputting the output torque of motor at time $t$ and the t- 1 time loaded torque, the rotational angular velocity of propeller $\omega_{t-1}$ into the " the angular accelerated speed of motor "calculated module to calculate the of hydraulic motor $\dot{\omega}$ at time $t$.

- Twelfth, inputting the angular accelerated speed $\dot{\omega}$ into the angular velocity of motor " calculated module to calculate the angular velocity of the hydraulic $\omega_{t}$ motor at time $t$.

- Thirteenth, inputting the thrust coefficient $K_{\mathrm{T}}$ at time $\mathrm{t}$ and the angular velocity of propeller $\omega_{t}$ into the "propeller thrust" calculated module to calculated the propeller thrust at time $t$.

- Fourteenth, inputting the torque coefficient $K_{\mathrm{M}}$ and the rotational speed of propeller $\omega_{t}$ at time $t$ into the "propeller torque" calculated module to calculate the torque of propeller $M_{t}$ at time $t$.

- Fifteenth, initializing the system again and continuing the iteration.

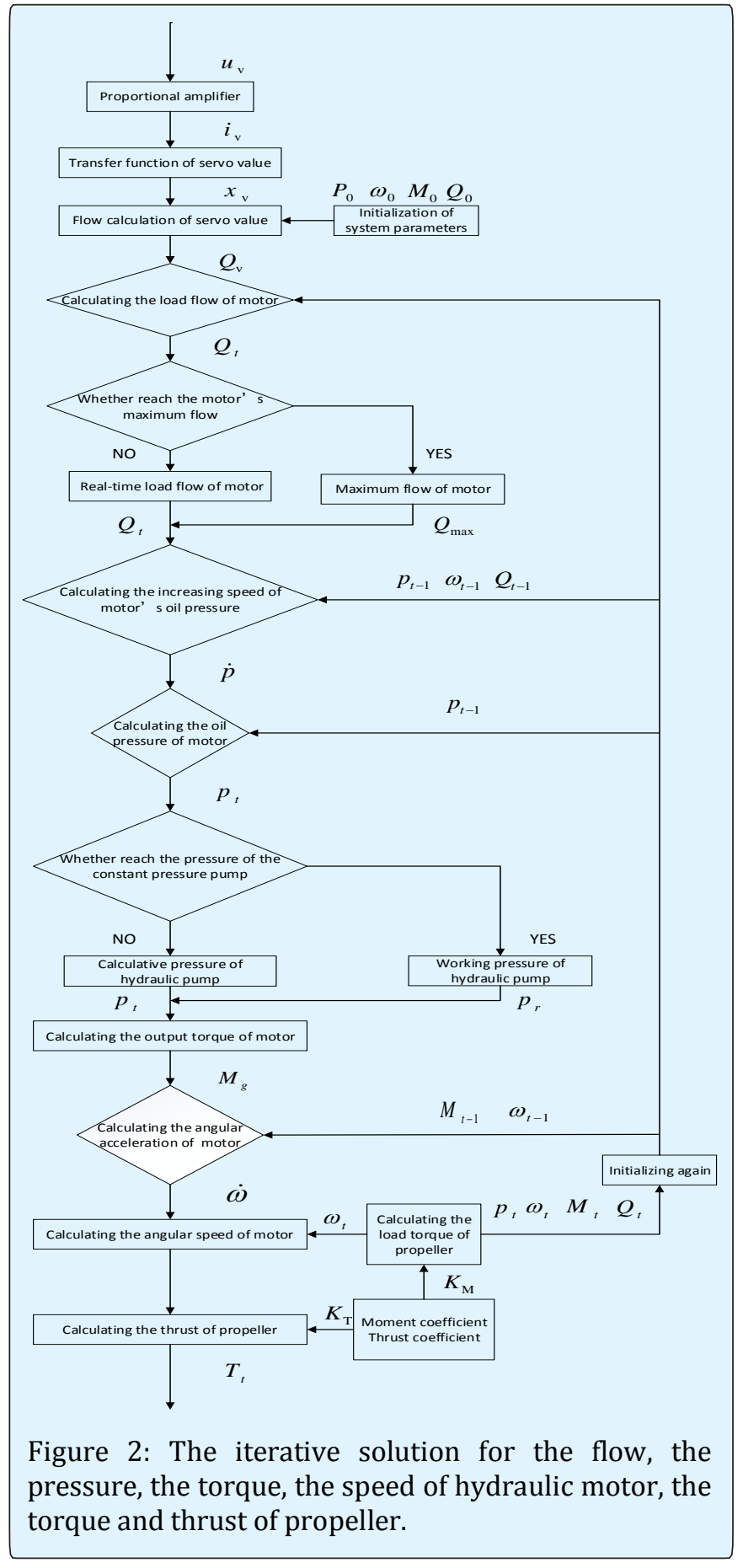

\section{Results and Analysis of Simulation}

\section{Analysis for Dynamic Responsive Simulation of Propeller under Different Controlled Voltage}

When the inlet speed of propeller is zero, the control voltage of servo valve is a step signal:-5V, $-3 \mathrm{~V},-1 \mathrm{~V}, 1 \mathrm{~V}, 3 \mathrm{~V}$, 


\section{International Journal of Oceanography \& Aquaculture}

$5 \mathrm{~V}$, the results of simulation are shown as Figures 3-8. Then analyzing the dynamical responsive processes and characteristics of the flow, the pressure, the torque, the speed, the torque of hydraulic motor and the thrust, the torque of propeller under the control of the step signal.

As can be seen in (Figure 3) under the control of a $5 \mathrm{~V}$ step signal, the pressure of hydraulic motor rises rapidly from zero. However, the pressure of motor is no longer increasing after $320 \mathrm{bar}$ since the working pressure limits of the hydraulic system. And it keeps at $320 \mathrm{bar}$ for some time and then decreases to a steady pressure 305bar slowly.

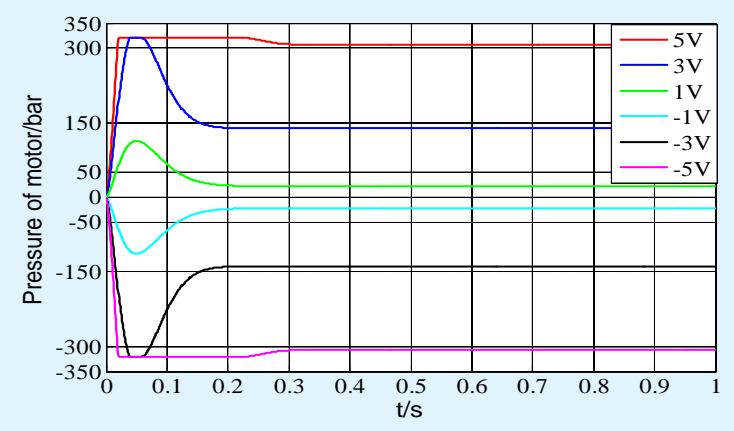

Figure 3: The pressure of motor under different control voltages.

As can be seen in (Figure 4) when the control voltage is a $5 \mathrm{~V}$ step signal, the flow of motor increases rapidly from zero. But at the time $t=0.02 \mathrm{~s}$, there appears a slight fluctuation due to the pressure of motor is limited by the motor's maximum flow. Under the load of propeller, the steady flow of hydraulic motor is about $54 \mathrm{~L} / \mathrm{min}$.

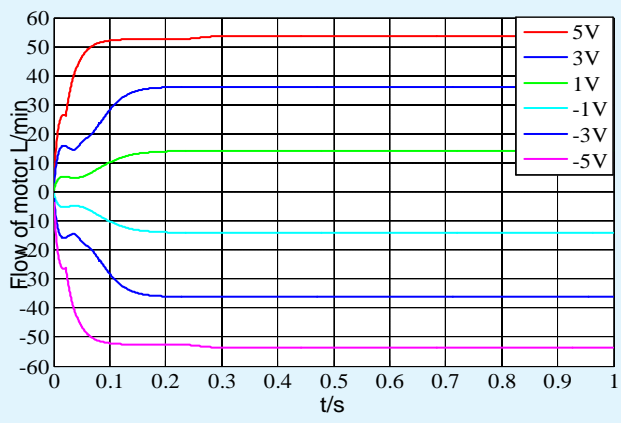

Figure 4: The floe of motor under different control voltages.
As can be seen in (Figure 5) when the control voltage is a $5 \mathrm{~V}$ step signal, the output torque of motor increases rapidly from zero. The maximum output torque of hydraulic motor is $160 \mathrm{~N} \cdot \mathrm{m}$ due to the value is limited by the work pressure of hydraulic system ; With the increasing of motor rotational speed, the output torque of motor begins to decrease and eventually keeps at a steady value $154 \mathrm{~N} \cdot \mathrm{m}$.

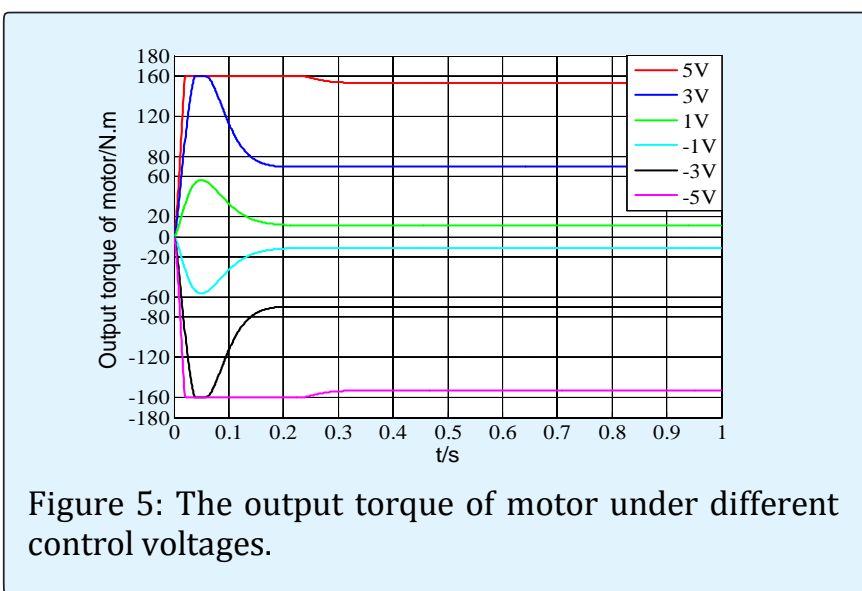

In summary, as can be seen in Figures 3-5 under the condition that the propeller speed is zero, when the $u_{\mathrm{v}} \geq 0$, the steady pressure, the flow and the torque of the hydraulic motor's response increase with the increasing of step control voltage. But the step control voltage of hydraulic propeller must satisfy the following condition:

$$
\left|u_{\mathrm{v}}\right| \leq 5 \mathrm{~V}
$$

If this condition is not satisfied the formula (11), a saturation of the pressure, the flow and the torque of motor will be caused, thereby causing a failure of the control for the propeller. Therefore, the output of desired thrust for the horizontal propeller should be made to satisfy the following constraints when designing the algorithm of the thrust allocation:

$$
\left|T e_{i}\right| \leq 6000 \mathrm{~N}(12)
$$

As can be seen in Figure 6 When the control voltage is a $5 \mathrm{~V}$ step signal, the rational speed of motor (the propeller speed) increased from zero gradually and slowly, and then quickly. Finally the rational speed of motor increased to a stable value (about 1740rpm), the adjustment time of its response is about $0.35 \mathrm{~s}$. The 
rotational speed of the horizontal propeller should satisfy the following constraints:

$$
|n| \leq 1740 \operatorname{rpm}(13)
$$

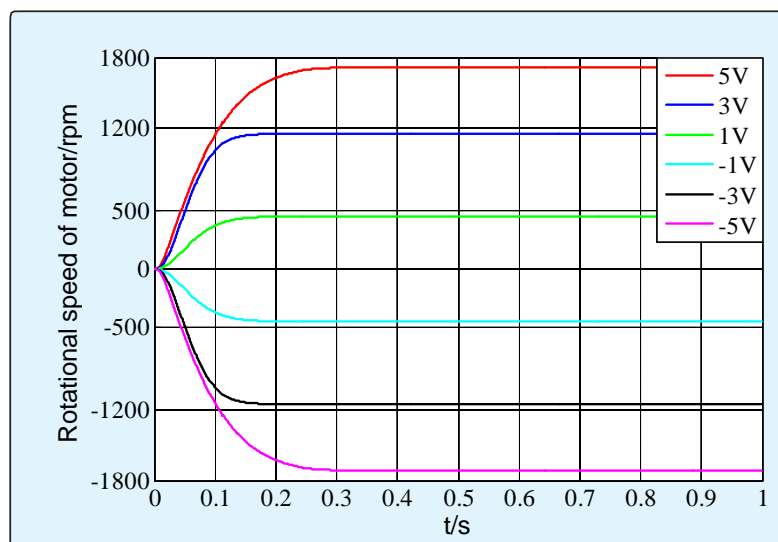

Figure 6: The rotational speed of motor under different control voltages.

As can be seen in Figure 7 when the control voltage is a $5 \mathrm{~V}$ step signal, the torque of propeller increases slowly from zero, then increases rapidly. Finally the load torque increases to a steady value about $150 \mathrm{~N} \cdot \mathrm{m}$.

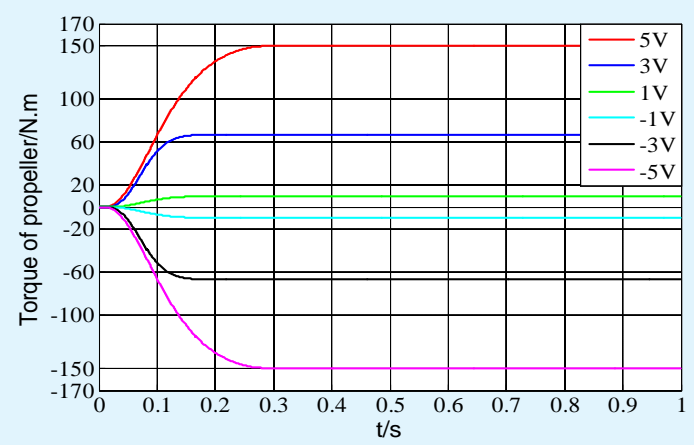

Figure 7: The torque of propeller under different control voltages

As can be seen in Figure 8 When the control voltage is a $5 \mathrm{~V}$ step signal, the thrust of propeller increases slowly from zero, and then increases rapidly. Finally the thrust increases to a steady value about $6000 \mathrm{~N}$.

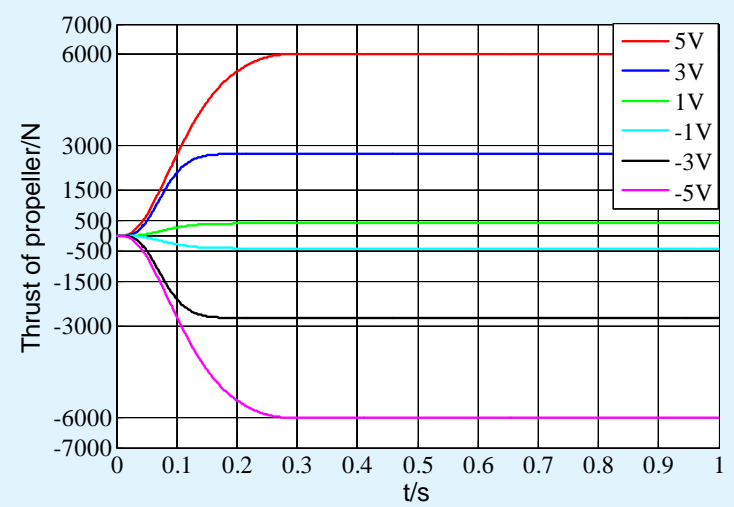

Figure 8: The thrust of propeller under different control voltages

As can be seen from Figure 8 the maximum rising velocity of thrust should be the red curve (response of the $5 \mathrm{~V}$ signal step) which should satisfy the following formula:

$$
\left|\frac{d\left(T_{i}\right)}{d t}\right| \leq 40000 \mathrm{~N} / \mathrm{s}(14)
$$

When designing the thrust allocation, the rising velocity of desired thrust should satisfy the following constraint:

$$
\left|\frac{d\left(T e_{i}\right)}{d t}\right| \leq 40000 \mathrm{~N} / \mathrm{s}
$$

In summary, as can be seen in the (Figures 6-8) when the speed of the propeller is zero, the steady response value of the rotational speed, the torque and the thrust increases with the increasing of the step signal; the adjust time of the is about $0.35 \mathrm{~s}$; under the control of a step signal, the thrust response, the speed and the torque of propeller increase from zero slowly, and then increases rapidly, finally increase to a stable value steadily. Therefore, it's not reasonable to assume that the output response of propeller thrust is a proportional link or a link whose thrust is constrained by the rising velocity $[2,3]$. 


\section{International Journal of Oceanography \& Aquaculture}

\section{Dynamical Responsive Simulation of the Hydraulic Propeller and Contrastive Analysis of the Experimental Results}

When the inlet speed of propeller is zero, the control voltages of servo valve are $0 \mathrm{~V}, 0.5 \mathrm{~V}, 1 \mathrm{~V}, 1.5 \mathrm{~V}, 2 \mathrm{~V}, 2.5 \mathrm{~V}, 3 \mathrm{~V}$, $3.5 \mathrm{~V}, 4 \mathrm{~V}, 4.5 \mathrm{~V}, 5 \mathrm{~V}$, analyzing the relationship between the steady thrust of hydraulic propeller and the flow of motor, the pressure of motor. The comparison with the results of tank test given by the company SMD is shown in Figures 9-11 [13].

As shown in Figure 9 is the simulation and experimental results of relationship between the pressure of hydraulic motor and the response of propeller thrust. Among them, the red line represents the tank test results of HTE380BA-32 hydraulic propeller given by the company SMD. The blue line represents the simulation results of the model established in this paper. From the comparison of the two curves can be seen: there has a linear relationship between the pressure of motor and the steady response of propeller thrust. The simulated results of steady-state response for the propeller thrust is identical well to the experimental results, the error is minimal.

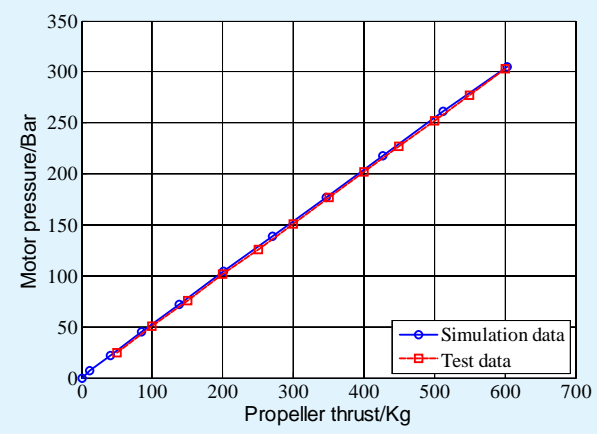

Figure 9: The relationship between the motor pressure and the propeller thrust

As shown in Figure 10 is the simulation of the experimental results and the relationship between the flow of hydraulic motor and the steady-state response of the propeller thrust. Among them, the red line represents the tank test results of HTE380BA-32 hydraulic propeller. The blue line represents the simulation results of the model established in this paper. As can be seen from the figure: there has a typical non-linear relationship between the flow of motor and the steady-state responsive value of propeller thrust, but the simulation results and the experimental results are basically coincident, the error is less than $1 \%$.

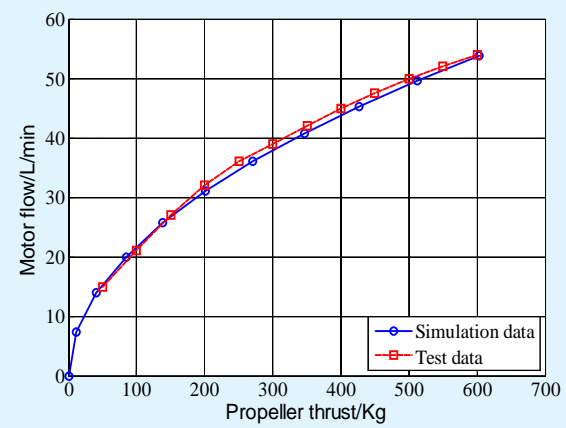

Figure 10: The relationship between the motor flow and the propeller thrust

As shown in Figure 11 is the simulation of the experimental results and the relationship between the rotational speed of hydraulic motor and the steady-state response value of the propeller thrust. Among them, the blue line represents the results of tank test for HTE380BA-32 hydraulic propeller. The red line represents the simulation results of the model established in this paper. As can be seen from the figure there has a typical non-linear relationship between the rotational speed of motor and the responsive steady-state value of the propeller thrust, but the simulated results and experimental results are basically coincident, the error is less than $1 \%$.

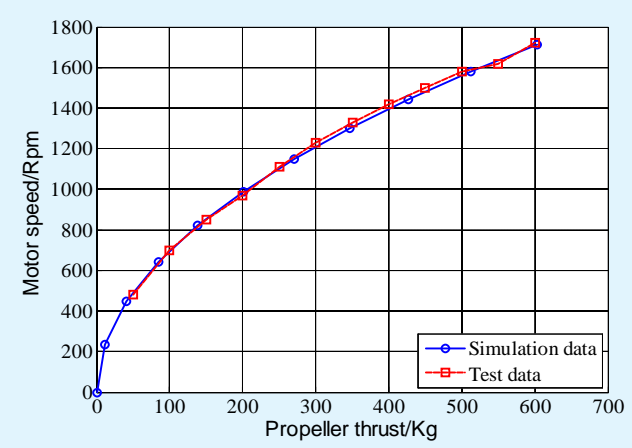

Figure 11: The relationship between the rotational speed of the motor and the propeller thrust

\section{The Relationships between the Control Voltage of Servo Valve and the Propeller Thrust}

According to the results of hydraulic propeller controlled by a servo valve simulated and analyzed in section 4.1 and section 4.2 , we can get the relationship 
between the control voltage and the actual thrust of propeller showed in Figure 12. As can be seen in Figure 12 , there has a typical non-linear between the steady thrust of hydraulic propeller and the control voltage which can be described by the piece wise function. After the fitting of curves, we can get the following formula:

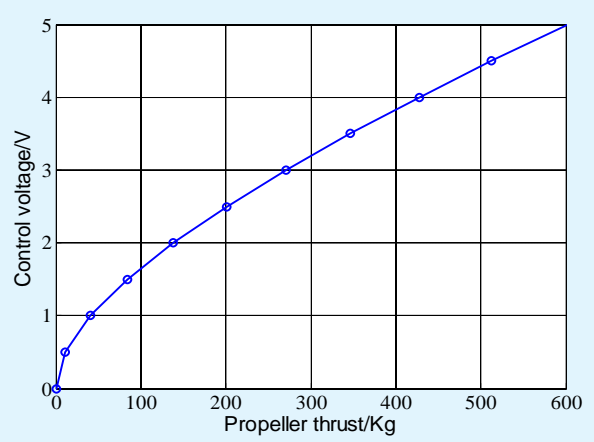

Figure 12: The relationship between the propeller thrust and the control voltages.

$u_{\mathrm{v}}=f\left(T_{i}\right)=\left\{\begin{array}{lc}-2.8 \times 10^{-6} x^{2}+0.0085 x+0.892 & 130<T_{a} \leq 600 \\ -2.4 \times 10^{-5} x^{2}+0.0145 x+0.442 & 50<T_{a} \leq 130 \\ -0.6 \times 10^{-3} x^{2}+0.0513 x & 0 \leq T_{a} \leq 50\end{array}\right.$

After designing the thrust allocation on the basis of the constrained conditions (12) and (14), the relationship between the desired thrust and the control voltage should satisfy the formula (16). "The controller of propeller" in figure 2 can be calculated by formula (16).

\section{Conclusions}

Through the modeling of dynamical system and the analysis of responsive simulation for the hydraulic propeller controlled by a servo valve, we can get the following conclusions:

1) This article introduced the dynamical loaded characteristics of the propeller into the modeling for the dynamic systems of hydraulic propeller, and analyzed the simulation for the dynamical system of hydraulic propellers under different control voltages. The study for the control of hydraulic propellers has a high engineering value.

2) Due to the limits of the rated work-pressure of hydraulic systems and the maximum flow of the hydraulic motor, the maximum thrust of hydraulic propellers should satisfy the constraints of formula
(12), the maximum outputting rational speed should satisfy the constraints of formula (13).

3) When the control voltage changes, the simulation results of the steady-state thrust, the rotational speed and the flow are basically identical to the tank test results of the actual propeller, the accuracy and credibility of this paper can be indicated preliminary.

4) A simplified constraint for the thrust allocation of the work-class ROV is established which was shown in the formula (12) and (15); a mathematical model for the control functions of hydraulic propellers as shown in the formula (16) which had a guiding significance and engineering value to the study for the thrust allocations of the work-class ROV .

\section{Acknowledgements}

The authors are grateful to the Marine Engineering Equipment Scientific Research Project of Ministry of Industry and Information Technology of PRC, the National Science and Technology Major Project of China (Grant N0. 2016ZX05057020).

\section{References}

1. Tor A Johansen, Thor I Fossen (2013) Control allocation-A survey. J Automatic 49: 1087-1103.

2. FAN Shibo (2013) Research on motion control and hydro-dynamic tests of deep-sea fishing type ROV [D], $\mathrm{PhD}$ Thesis of Shanghai Jiaotong University, Shanghai, pp: 1-16.

3. Fossen Thor I (2011) Handbook of Marine Craft Hydrodynamics and Motion Control [M], New York, John Wiley \& Sons Ltd 1-10, New York.

4. Yang Shi-zhi, Wang Lei, Zhang Shen (2001) Optimal thrust allocation based on fuel-efficiency for dynamic positioning system, J. Journal of Ship Mechanics 15(3): 217- 226.

5. Serdar Soylu, Bradley J Buckham, Ron P Podhorodeski (2008) A chattering-free sliding-mode controller for underwater vehicles with fault-tolerant infinity-norm thrust allocation. J Ocean Engineering 35: 1647-1659.

6. Liu Xijia (2004) Design and Simulation of Work-class ROV Hydraulic Propulsion System Based on AME Sim[D], Master's degree thesis of Ocean University of China, Qingdao. 


\section{International Journal of Oceanography \& Aquaculture}

7. Wei Yanhui, Gao Weihang, Liu Hewei (2015) A Propulsion System for Deep-sea ROV [P]. China patent.

8. Ji Yulong, Sun Yuqing, Chen Haiquan (2008) Research on control and simulation of integrated hydraulic propulsion ships. Journal of Harbin Engineering University 29(5): 437- 443.

9. Ma Laihao (2014) Study on the Propeller Load Simulation of the Marine Hydraulic Propulsion System [D]. Master's degree thesis of Dalian maritime university, Dalian.

10. Pengwei, Luobin (2010) Digital Simulation of Marine Propeller Load Characteristics, J. Ship and Ocean Engineering 39(2): 64-67.
11. (2012) Soil Machine Dynamics Limited. CURVETECH THRUSTER TECHNICAL MANUAL HTE300BA32MKII[R]. Newcastle: SMD.

12. (2014) Roxroth Bosch Group. A2FM Fixed motor [R]. Germany: Roxroth Bosch Group.

13. Liang Lihua (2005) Hydraulic and electro-hydraulic servo system $[\mathrm{M}]$, Press of Harbin Engineering University, Harbin.

14. Sheng Zhenbang, Liu yingzhong (2004) Shipping Principle. Press of Shanghai Jiaotong University, Shanghai.

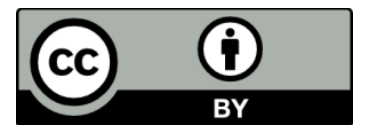

